\title{
UMA ANÁLISE ESTRATÉGICA - ESTUDO DE CASO HSBC BRASIL
}

\author{
AN STRATEGIC ANALYSIS - CASE STUDY OF HSBC BRAZIL
}

\section{Elizabeth Freitas Rodrigues}

Pontifícia Universidade Católica do Rio de Janeiro, e Centro Federal de Educação Tecnológica - Celso Suckow da Fonseca - CEFET-RJ

\author{
Gabriel Levrini \\ Pontifícia Universidade Católica do Rio de Janeiro
}

\section{Mario Domingues de Paula Simões}

Pontifícia Universidade Católica do Rio de Janeiro

\section{RESUMO}

O presente trabalho faz uma análise estratégica da subsidiária do HSBC Holding no Brasil, no período de 2006 a 2009, para evidenciar como o banco conseguiu adaptar-se à nova realidade dos mercados em que opera. Também é feita uma análise das mudanças estratégicas que foram realizadas e, suas implicações no desempenho da empresa. 0 estudo baseou-se no ferramental GI de Macedo-Soares (2005), que contempla os construtos de Fahey \& Randall (1998) e Hofer \& Schendel (1978). 0 estudo de caso consolidou-se através de investigação documental e levantamento de percepções, baseado em questionários semi-estruturados e entrevistas com executivos seniores do banco. Os resultados evidenciaram que o banco busca uma estratégia de posicionar-se globalmente, dando ênfase nos países em desenvolvimento, entretanto demonstra uma deficiência na circulação de informações estratégicas nos diversos níveis hierárquicos. Quanto aos processos de inovação, não foi evidenciado que o banco acompanhe as tecnologias inovadoras implantadas por seus concorrentes.

Palavras-chave: Análise estratégica. Gerenciamento estratégico. Desempenho estratégico.

\begin{abstract}
The present work is a strategic review of HSBC Holding's subsidiary in Brazil during 2006-2009, to show how the bank managed to adapt to new market realities in which it operates. It is also an analysis of strategic changes made and their implications for company performance. The study was based on the tooling GI de Macedo Soares (2005), which includes the constructs of Fahey \& Randall (1998) and Hofer \& Schendel (1978). The case study was consolidated through documental research and a survey, based on semi-structured questionnaires and interview with bank's senior executive. The results showed that the bank pursues a strategy to position itself globally, with emphasis on developing countries, however demonstrates a deficiency in the strategic information flow at various hierarchical levels. As for innovation processes, it was not evident that the bank follows the innovative technology implemented by its competitors.
\end{abstract}

Keywords: Strategic analysis. Strategic management. Strategic performance. 


\section{INTRODUÇÃO}

A globalização trouxe consigo uma necessidade premente às organizações de aumentarem suas escalas de operações visando atender seus clientes de forma global, e isso acarretou a necessidade de aumentar sua participação nos diferentes mercados do mundo, encontrando características peculiares de cada mercado, no que diz respeito as políticas governamentais diferentes, mercados abertos e fechados, privatizações, e diferentes taxas de inflação. Todos estes fatores impuseram estratégias diferentes ao setor bancário adaptando a sua maneira de atuar em cada mercado em que operam porem estrategicamente mantendo sua visão global. O slogan do HSBC Holdings caracteriza muito bem esse pensamento, The World's local bank.

De fato, com o HSBC Holding não foi diferente, sendo que hoje possui a condição de segunda instituição financeira mundial. A partir da década de 1990, com o comando de Sir John Bond, o grupo HSBC iniciou uma forte ofensiva visando tornar-se um poderoso player global financeiro. Na sua estratégia de lançar-se como um banco global, posicionou-se em mercados maduros (USA e Europa) com aquisições de instituições com forte presença no financiamento de Bens de Consumo. Também manteve o foco de uma de suas principais prioridades estratégicas: entrar ou aumentar sua presença em mercados emergentes - os países que compõem o bloco BRIC (Brasil, Rússia, Índia e China) - e expandir assim suas atividades. Entretanto a crise econômica mundial de 2008 mudou alguns cenários e trouxe consigo alguns intervenientes que afetaram não só o HSBC mas o mercado financeira mundial como um todo.

O objetivo deste artigo é fazer uma análise estratégica de uma das subsidiárias do HSBC Holding - o Banco HSBC Brasil - , no período de 2006 a 2009 - considerando a crise econômica mundial neste período, para evidenciar como o banco conseguiu adaptar-se à nova realidade dos mercados em que opera. Também é feita uma análise das mudanças estratégicas que foram realizadas e suas implicações no desempenho da empresa.

O caso do HSBC Brasil é interessante por se tratar da sua atuação no único BRIC da América Latina - o Brasil -, onde a crise, segundo dados, afetou menos os bancos mundiais.

\section{UM PANORAMA GERAL SOBRE O HSBC BRASIL E O CONTEXTO BRASILEIRO}

Desde o inicio do Plano Real em 1994 o setor de Serviços Financeiros no Brasil passou por grandes transformações. Os leilões de privatização de Bancos Estaduais abriram a oportunidade para grandes instituições estrangeiras se instalarem no Brasil e obrigarem os bancos nacionais - públicos e privados - a defenderem suas posições. Ao mesmo tempo as altas taxas de juros travavam a expansão do crédito e aumentavam a competição setorial. Quinze anos depois, o cenário mudou totalmente.

No início do Plano Real havia, no país, 241 bancos. Hoje este número não chega a 180 bancos. No entanto, poucos bancos estrangeiros conseguiram conquistar uma participação relevante no mercado financeiro brasileiro. As exceções são: o Banco Santander que comprou o Banespa no leilão de privatização e assumiu o Banco Real após comprar globalmente o holandês ABN; o Banco HSBC com a compra do Bamerindus. Os grandes bancos brasileiros aumentaram a concentração em termos de créditos e ativos: os cinco maiores concentram no ano de 2009 cerca de $75 \%$ do setor contra menos de $50 \%$ em 1994.

A seguir apresenta-se o ranking dos bancos em Setembro de 2009. 
Tabela 1: Ranking dos Bancos por ativos - Base Setembro 2009

\begin{tabular}{|c|c|}
\hline Banco & Ativo em R\$ Bilhões \\
\hline Banco do Brasil & 583,33 \\
\hline Itaunibanco & 576,56 \\
\hline Bradesco & 425,96 \\
\hline Santander Brasil & 332,67 \\
\hline C.E.F & 323,61 \\
\hline HSBC Brasil & 106,15 \\
\hline Votorantim & 90,22 \\
\hline Safra & 66,48 \\
\hline Citibank & 41,91 \\
\hline
\end{tabular}

Fonte: Bacen - Banco Central do Brasil - www.bcb.org.br - recuperado em 21.11.2009.

Na continuidade do sucesso do Plano Real, os juros básicos começaram a diminuir, apesar de ainda elevados para o consumidor final, provocando um acirramento da concorrência e uma diminuição da rentabilidade dos bancos neste período pós-inflacionário. A reforma bancária iniciada no governo do Presidente Fernando Henrique Cardoso (1994 - 2002) provocou uma adequação rápida às regras da Basiléia que busca controlar o grau de alavancagem das operações bancárias através de maior transparência dos seus ativos e uma solidez maior no patrimônio líquido. Esta rápida adaptação e adequação as novas regras, não foi observada em nenhum outro país no mundo (Fortuna, 2009).

Esta solidez financeira provocou uma ampliação de serviços e de investimentos em tecnologia, valores estes que se incorporaram às novas demandas dos consumidores brasileiros - em 10 anos o acesso aos bancos pela Internet aumentou em 300\% chegando a cerca de 32 milhões de contas (Editora Três, 2009).

A solidez e a menor alavancagem dos bancos brasileiros, mostrou ser um valioso diferencial e uma vantagem competitiva importante, principalmente diante de seus concorrentes internacionais comprometidos com as dificuldades em suas matrizes durante a crise. 0 setor nacional passou quase incólume à crise mundial precipitada em setembro de 2008 a partir da falência do Lehman Brothers e desencadeou aquela que se consolidaria como sendo a pior crise financeira desde a década de 1920.

No inicio desta crise, os bancos privados brasileiros e estrangeiros se viram forçados a retrair-se, em virtude dos problemas das linhas de funding(captação) externas e da paralisação das operações de trade (comerciais) a nível global; porém a recuperação foi muito rápida sendo o Brasil o primeiro país no mundo a ter uma mudança positiva no investment grade: a Agencia Moddy`s seguindo o exemplo das outras duas grandes agências de classificação de risco, a Fictch e a Standard \& Poor, elevou o Brasil para BAA3 considerada grau de investimento (HTTP://www.valoronline.com.br - recuperado em 05/10/09).

\section{REFERENCIAL TEÓRICO}

A fim de que o assunto em pauta seja ampla e detalhadamente abordado, alguns conceitos centrais precisam ser definidos.

Para o conceito de estratégia, o estudo baseou-se em Macedo-Soares (2002), que se inspirou em Grant (1998), quando o define como um propósito unificador que dá coerência e direção às ações e decisões de uma organização, especialmente para alavancar e alocar os recursos/competências necessários para melhorar e sustentar sua performance, de acordo com sua visão e principais objetivos, à luz das 
condições ambientais externas e internas.

É importante que alguns dos conceitos de Michael Porter (1980) sejam explicitados no estudo, no que concerne notadamente sua classificação de atores estratégicos em: rival, cliente, fornecedor, novo entrante e substituto.

Outro conceito necessário de ser abordado, no que concerne aos atores estratégicos, é o de "complementor" que, segundo Bradenberger e Nalebuff (1997), é todo e qualquer produto que associado a outro torna o mesmo mais atrativo. No mercado financeiro isto se torna uma realidade e necessidade na oferta de produtos aos clientes.

Devem ser observados também os conceitos de Austin (1990), que confirma a relevância da necessidade de interdependência entre os fatores ambientais e a organização. 0 mesmo ressalta que a especificidade dos fatores macro-ambientais, econômico, político, cultural e demográfico - que devem ser acompanhados pelo reconhecimento de suas interrelações.

De acordo com Austin(1990) um gestor precisa conhecer todas estas vertentes e como as mesmas estão desenhadas para ter uma melhor visualização do ambiente. Esses fatores e suas inter-relações formam a natureza do negócio nos níveis nacional, internacional e da indústria, proporcionando uma lente de análise através da qual se enxergam todos os níveis.

0 presente estudo baseou-se no ferramental GI de análise estratégica de Macedo-Soares (2005), que contempla os construtos de Fahey \& Randall(1998) para caracterizar a estratégia e seus processos, quais sejam: (a) escopo - o segmento do mercado no qual a empresa deseja competir; (b) diferenciação competitiva - como a empresa deseja competir e como se diferenciará naquilo que está oferecendo ao mercado para atrair, ganhar e reter seus clientes e, (c) objetivos - o que a empresa deseja alcançar ou cumprir e como vem cumprindo tais objetivos.

O presente estudo utiliza uma abordagem consistente com o conceito de fit estratégico de Hofer \& Schendel (1978) que afirma que uma estratégia adequada deve estar relacionada tanto com o ambiente externo quanto com seus recursos internos, não deixando de analisar seus objetivos e processos. Está em linha com Barney (1996), segundo o qual uma estratégia boa - adequada - é uma estratégia que neutraliza ameaças e explora oportunidades, enquanto capitaliza as forças e evita ou minimiza fraquezas.

É importante observar que para que a análise da estratégia da organização seja feita com base no ferramental GI, faz-se necessária uma investigação sistêmica e interpretativa, ou seja, integram-se conceitos das diversas escolas de estratégia, como as já citadas anteriormente, possibilitando assim uma análise mais aprofundada da referida organização.

\section{POSICIONAMENTO TEÓRICO}

Em finanças, o risco é a probabilidade de não obter o retorno esperado no investimento realizado. 0 risco é definido como a própria variância do retorno. Quanto maior a amplitude desse desvio, maior será o resultado exigido para compensar o risco assumido. Basicamente, dois fatores causam o desvio do retorno. Um refere-se às características intrínsecas da operação ou da contraparte, como a garantia prestada ou a capacidade de pagamento do devedor, chamado de risco idiossincrático, não-sistemático ou diversificável. 0 outro é não controlável, inerente ao ambiente ou ao sistema, conhecido como risco sistemático ou não diversificável (MARTINS; ASSAFNETO, 1986, p. 467 apud CAPELLETO e CORRAR, 2008).

De acordo com Ross, Westerfield e Jaffe (1995, p. 233) um risco sistemático é qualquer risco que afeta um grande número de ativos, e cada um deles com maior ou menor intensidade. Esse enfoque ressalta que o risco está relacionado às possibilidades de variação na conjuntura, que, por sua vez, é diretamente afetada pelo nível de credibilidade no sistema como um todo. 
O HSBC Holdings, assim como todas as demais instituições financeiras, foi afetado pelo ambiente político-econômico, ocasionado pela crise econômica mundial que se iniciou no ano de 2008, e com isto teve seu desempenho afetado. 0 risco do seu negócio cresceu de forma acelerada e, desgastes organizacionais foram inevitáveis, tais como demissões, revisão de estrutura organizacional, entre outros.

Entretanto vale ressaltar, que a estrutura sólida - tanto organizacional e patrimonial - conseguida pela qualidade de gestão e, seu desempenho histórico, principalmente nos anos anteriores a crise (2006 e 2007), permitiu ao HSBC Holdings uma situação diferenciada para enfrentar a crise econômica, como é evidenciado ao longo do trabalho.

Este estudo faz uma análise dos principais indicadores estratégicos do banco a fim de demonstrar como o mesmo atuou no período de 2006-2009 e, como vem reagindo neste momento.

\section{METODOLOGIA DA PESQUISA}

Para esta pesquisa foi feita, primeiramente, uma revisão da literatura sobre gerenciamento estratégico a fim de possibilitar uma análise da estratégia estabelecida pelo HSBC Brasil. Esta análise é feita sob a ótica do ferramental GI (Macedo Soares -2000), evidenciando toda a rede de valor da organização.

É feito um estudo de caso do HSBC Brasil e para tal têm-se como base alguns relatórios específicos da área financeira do Banco Central, Recuperado em Setembro, 2009, de http://www.bcb.org.br. Algumas informações pertinentes à crise econômica mundial e informações do Banco HSBC foram recuperadas em Outubro, 2009, de http://www.hsbc.com.br , assim como entrevistas feitas com executivos do banco. É utilizado vasto documental da mídia, jornais, revistas especializadas, sites e associações de classe.

Foram efetuadas duas entrevistas com executivos seniores do banco, conduzidas através de um roteiro semi-estruturado, visando entender o contexto pré e pós-crise do HSBC Brasil e suas principais ações estratégicas durante o período estudado.

Para que este objetivo maior fosse atingido, a pesquisa teve como objetivos intermediários: (1) análise dos fatores internos da empresa, análise dos fornecedores, complementores e concorrentes; e (2) avaliação das aquisições feitas pelo banco no mercado brasileiro.

A pesquisa pode estar sujeita a algumas limitações, visto que não é possível tomarcomo absolutamente isentas as entrevistas dos executivos, os quais respondem aos questionamentos baseados em fatos, mas também em suas percepções. De qualquer forma, como as fontes usadas foram variadas e a metodologia permitiu uma observação bastante específica da organização, acredita-se que seja possível superar tais limitações referentes ao método do estudo de caso.

\section{ANÁLISE DA ESTRATÉGIA DO HSBC BRASIL ATRAVÉS DO FERRAMENTAL GI}

\section{CARACTERÍSTICAS DA ESTRATÉGIA}

De acordo com o primeiro passo do modelo GI, é importante que seja definida a estratégia do banco. Com base na tipologia de Mintzberg (1988) a estratégia do banco HSBC Brasil pode ser definida como uma estratégia de diferenciação por preço. Percebe-se então que o banco deve buscar constantemente a criação de valor para o cliente e os stakeholders, demonstrando assim que a prioridade de suas ações está nestes atores.

0 resultado das pesquisas evidenciou também que o banco possui uma gama diversificada de produtos, atendendo a demanda de pessoas físicas e jurídicas, além de uma divisão de seguros, onde planos de previdência são oferecidos ao mercado e ainda os concorrentes são usados para complementar seus produtos. 
Atualmente o banco está presente em 565 municípios, possuindo 933 agências e 457 postos de atendimento, com uma base de clientes de cerca de 2,9 milhões de pessoas físicas e 313 mil de pessoas jurídicas.

Atualmente o banco busca uma estratégia de posicionar-se globalmente ao redor do mundo, dando ênfase, entretanto, nos países em desenvolvimento.

\section{IMPLICAÇÕES ESTRATÉGICAS DOS FATORES ORGANIZACIONAIS}

De acordo com o segundo passo do modelo GI, as implicações estratégicas dos fatores organizacionais - Hard e Soft - do HSBC Brasil são analisadas. Por meio das tabelas a seguir, tais implicações podem ser evidenciadas.

As entrevistas puderam revelar que apesar da matriz do HSBC na Inglaterra dar autonomia aos seus bancos locais, os vários níveis hierárquicos existentes na estrutura organizacional dificultam a descentralização. 0 fato de possuir um alinhamento deficitário entre os objetivos operacionais e estratégicos dificulta ainda mais o fator descentralização de poder, levando a um baixo empowerment por parte dos níveis gerencial e operacional (vide tabela 2). Os processos funcionais, apesar de documentados ainda engessam um pouco a estrutura, não permitindo uma flexibilização por parte da gerência. Em contrapartida, o banco incentiva treinamentos gerenciais e técnicos, mas não dá foco aos treinamentos para desenvolvimento de competências voltadas a satisfação do cliente.

Tabela 2 - Atributos necessários para Variáveis Hard para bancos de varejo

\begin{tabular}{|c|c|c|c|}
\hline Variáveis & Atributos necessários & Forças do HSBC & Fraquezas do HSBC \\
\hline \begin{tabular}{c|} 
Estrutura \\
Organizacional
\end{tabular} & $\begin{array}{l}\text { Estrutura descentralizada e } \\
\text { processos de controle bem } \\
\text { definidos. }\end{array}$ & $\begin{array}{c}\text { O Brasil possui um certo } \\
\text { grau de autonomia dado } \\
\text { pela matriz. }\end{array}$ & $\begin{array}{c}\text { O grupo no Brasil possui uma } \\
\text { estrutura hierárquica com muitos } \\
\text { níveis, dificultando a } \\
\text { descentralização. }\end{array}$ \\
\hline $\begin{array}{l}\text { Sistemas de } \\
\text { medição de } \\
\text { performance }\end{array}$ & $\begin{array}{c}\text { Devem estar alinhados com todos } \\
\text { os subsistemas e ainda com os } \\
\text { objetivos estratégicos do banco. }\end{array}$ & & $\begin{array}{l}\text { O alinhamento entre os objetivos } \\
\text { estratégicos com os operacionais é } \\
\text { deficitário }\end{array}$ \\
\hline Equipe & $\begin{array}{c}\text { Deve existir uma integração entre } \\
\text { os departamentos e um alto grau } \\
\text { de empowerment }\end{array}$ & & $\begin{array}{l}\text { O grau de empowerrment ainda é } \\
\text { baixo, tolindo algumas iniciativas. }\end{array}$ \\
\hline Processos & $\begin{array}{l}\text { Características inter-funcionais } \\
\text { são documentadas e publicadas. }\end{array}$ & $\begin{array}{c}\text { Muitos processos internos } \\
\text { são documentados e } \\
\text { divulgados }\end{array}$ & $\begin{array}{l}\text { Processos funcionais muitos } \\
\text { amarrados, inviabilizando } \\
\text { flexibilização dos mesmos. }\end{array}$ \\
\hline \begin{tabular}{|c|} 
Sistemas de \\
Reconhecimento \\
e Recompensa
\end{tabular} & $\begin{array}{c}\text { Avaliação de desempenho e } \\
\text { sistemas de remuneração } \\
\text { compatível com o sistema geral do } \\
\text { banco de medição de desempenho. }\end{array}$ & & $\begin{array}{l}\text { Os sistemas de reconhecimento } \\
\text { focam em resultados operacionais, } \\
\text { mas não atrelam os mesmos a } \\
\text { satisfação do cliente. }\end{array}$ \\
\hline \begin{tabular}{|c|} 
Sistemas de \\
desenvolvimento \\
Educacional
\end{tabular} & $\begin{array}{c}\text { Educação continuada visando } \\
\text { melhoria contínua dos processos e } \\
\text { aquisição de novas competências. }\end{array}$ & $\begin{array}{c}\text { Incentivam treinamentos } \\
\text { gerenciais e técnicos } \\
\text { Fazem uso de ferramentas } \\
\text { de aprendizagem pela } \\
\text { internet. }\end{array}$ & $\begin{array}{c}\text { Os treinamentos não focam em } \\
\text { desenvolver competências para } \\
\text { atendimento de satisfação do cliente. }\end{array}$ \\
\hline
\end{tabular}

Os fatores organizacionais, dentro de variáveis SOFT foram identificados, através de entrevistas de onde surgiram alguns pontos fracos tais como: estilo de liderança onde ainda impera um autoritarismo sem permitir iniciativas próprias por parte dos colaboradores. Outro ponto fraco revelado pela pesquisa, diz respeito à baixa circulação de informações estratégicas, evidenciando deficiências também na comunicação interna e externa. Ainda fica clara a orientação da cultura da empresa voltada para resultados financeiros, não se preocupando com a satisfação do cliente. Um ponto forte identificado foi o compromisso de executivos do banco para as práticas empresariais éticas. (vide Tabela 3). 
Tabela 3 -Atributos necessários para Variáveis Soft para bancos de varejo

\begin{tabular}{|c|c|c|c|}
\hline Variáveis & Atributos necessários & Forças do HSBC & Fraquezas do HSBC \\
\hline $\begin{array}{c}\text { Cultura } \\
\text { Organizacional }\end{array}$ & $\begin{array}{c}\text { Cultura de melhoria de } \\
\text { desempenho deve ser clara para } \\
\text { todos. Priorização da } \\
\text { Responsabilidade social e ética }\end{array}$ & $\begin{array}{l}\text { A ética é bastante evidente no } \\
\text { comportamento dos gestores, assim } \\
\text { como o respeito à legislação. }\end{array}$ & \\
\hline Estilo de liderança & $\begin{array}{c}\text { Compromisso dos líderes com a } \\
\text { estratégia de participação de } \\
\text { todos e incentivo a iniciativa } \\
\text { dos colaboradores }\end{array}$ & & $\begin{array}{c}\text { Predomina um estilo de } \\
\text { liderança autocrático, sem } \\
\text { muita preocupação em } \\
\text { motivar iniciativas }\end{array}$ \\
\hline \multirow[t]{2}{*}{ Comunicação } & $\begin{array}{l}\text { Inter-funcional, divulgando } \\
\text { sempre os objetivos } \\
\text { estratégicos, favorecendo o } \\
\text { feedback entre os níveis. }\end{array}$ & $\begin{array}{c}\text { As publicações de cunho gerencial e } \\
\text { operacional são amplamente } \\
\text { divulgadas pela intranet. }\end{array}$ & $\begin{array}{c}\text { Informações estratégicas } \\
\text { pouco circulam na } \\
\text { empresa }\end{array}$ \\
\hline & \begin{tabular}{|c|} 
Desenvolvimento e \\
consolidação da imagem do \\
banco e da marca em relação ao \\
público em geral.
\end{tabular} & $\begin{array}{l}\text { A imagem do banco vem sendo } \\
\text { bastante divulgada na mídia }\end{array}$ & $\begin{array}{c}\text { Muitos clientes ainda não } \\
\text { reconhecem o banco como } \\
\text { o segundo maior banco } \\
\text { mundial }\end{array}$ \\
\hline
\end{tabular}

Como pode ser observado nas tabelas 4 e 5 , foram colhidas informações sobre os fatores tecnológicos Hard e Soft. Para os fatores Hard, o banco possui somente pontos fortes no que tange a sistemas de relacionamento com o cliente, conectividade com os sistemas de pagamento do Banco Central, assim como o Home Banking pela internet e caixas eletrônicos, disponíveis para seus clientes.

Com relação aos fatores Soft, os dados apontaram para diversas forças em metodologias e processos, devido à importância atribuída pelo HSBC para o cumprimento das entidades reguladoras. Por outro lado, quando se fala de processos de inovação, percebe-se que o HSBC possui deficiências, visto que praticamente nenhuma evidência pode ser encontrada referente a novas tecnologias e novos produtos bancários. No meio bancário este setor é de vital importância, entretanto o HSBC limita-se a acompanhar as tecnologias inovadoras implantadas por seus concorrentes Itaunibanco e Bradesco.

Tabela 4 - Atributos necessários para Variável Tecnológica Hard para bancos de varejo

\begin{tabular}{|c|c|c|c|}
\hline Variáveis & Atributos necessários & Forças do HSBC & Fraquezas do HSBC \\
\hline $\begin{array}{c}\text { Tecnologia da } \\
\text { Informação }\end{array}$ & $\begin{array}{c}\text { Possui sistemas integrados, com } \\
\text { tempo de resposta baixo e fácil } \\
\text { acesso a funcionalidades adequadas } \\
\text { ao nível. }\end{array}$ & $\begin{array}{c}\text { Possui um sistema de } \\
\text { relacionamento com o cliente - } \\
\text { CRM, bastante eficiente. }\end{array}$ & \\
\cline { 2 - 4 } & $\begin{array}{c}\text { Conectividade externa com outros } \\
\text { bancos }\end{array}$ & $\begin{array}{c}\text { Possui conectividade com o } \\
\text { sistema de pagamentos do Banco } \\
\text { Central }\end{array}$ & \\
\cline { 2 - 5 } & $\begin{array}{c}\text { Acuracidade no sistema de } \\
\text { segurança }\end{array}$ & $\begin{array}{c}\text { Sistema de segurança com } \\
\text { certificação eletrônica e } \\
\text { criptografada }\end{array}$ & \\
\cline { 2 - 5 } & $\begin{array}{c}\text { Home banking através da internet } \\
\text { para os clientes }\end{array}$ & $\begin{array}{c}\text { Sistema de Home Banking com } \\
\text { acesso pela internet, bastante } \\
\text { eficiente. }\end{array}$ & \\
\hline
\end{tabular}


Tabela 5 - Atributos necessários para Variável Tecnológica Soft para bancos de varejo

\begin{tabular}{|c|c|c|c|}
\hline Variáveis & Atributos Necessários & Forças do HSBC & Fraquezas do HSBC \\
\hline $\begin{array}{l}\text { Metodologia e } \\
\text { Técnicas }\end{array}$ & $\begin{array}{l}\text { Desenvolvimento e implementação } \\
\text { de processos bancários, visando a } \\
\text { otimização, o cumprimento da } \\
\text { legislação e a redução de custos. }\end{array}$ & $\begin{array}{c}\text { Os gestores dão bastante } \\
\text { importância ao cumprimento das } \\
\text { regras que regulam o setor bancário } \\
\text { brasileiro. }\end{array}$ & \\
\hline Inovação & $\begin{array}{c}\text { Atividades permanentes de } \\
\text { investigação, desenvolvimento, } \\
\text { aquisição e adaptação de produtos } \\
\text { bancários e novas tecnologias. }\end{array}$ & & $\begin{array}{c}\text { O banco não tem a prática } \\
\text { de iniciativa de busca e } \\
\text { desenvolvimento de novas } \\
\text { tecnologias }\end{array}$ \\
\hline
\end{tabular}

Quanto ao fator Pessoas, a pesquisa evidenciou, através de entrevistas, que os executivos buscam a solução de problemas através de novas metodologias, possuem competências, mas não encontram espaço para dar um foco maior a orientação para a satisfação do cliente. Outro ponto forte evidenciado é que existe uma grande interação interpessoal e interdepartamental no banco. (Ver Tabela 6).

Tabela 6 - Atributos necessários para a variável Pessoas para bancos de varejo

\begin{tabular}{|c|c|c|c|}
\hline Variável & Atributo necessário & Forças do HSBC & Fraquezas do HSBC \\
\hline $\begin{array}{c}\text { Competência, } \\
\text { habilidade e } \\
\text { atitude. }\end{array}$ & $\begin{array}{c}\text { Experiência e conhecimento para } \\
\text { aplicar em novas metodologias e } \\
\text { processos visando a satisfação de } \\
\text { todas as partes interessadas. }\end{array}$ & $\begin{array}{c}\text { Os executivos não têm se sentido } \\
\text { problemados a buscarem a solução de o alcance dos } \\
\text { objetivos. }\end{array}$ & $\begin{array}{c}\text { Não há a busca por } \\
\text { profissionais com } \\
\text { competências de } \\
\text { orientação ao cliente. }\end{array}$ \\
\cline { 2 - 4 } & $\begin{array}{c}\text { Interação e habilidade de } \\
\text { comunicação inter-pessoal }\end{array}$ & $\begin{array}{c}\text { Há uma forte interação interpessoal } \\
\text { e interdepartamental }\end{array}$ & \\
\hline
\end{tabular}

\section{IMPLICAÇÕES ESTRATÉGICAS DOS FATORES AMBIENTAIS}

Baseado no modelo GI, algumas implicações estratégicas dos fatores macro-ambientais e seus atores foram também identificadas. Para o período em que se refere o presente estudo, ficou evidente que as maiores oportunidades são oriundas dos fatores político e econômico visto que, mesmo com a crise financeira mundial o Brasil vem se demonstrando um país com estabilidade política e com uma tendência favorável ao mercado econômico, favorecendo as organizações já estabelecidas em seu mercado.

Tal estabilidade econômica referendada pelo Banco Central e pelo próprio Governo Federal tem sido favorável ao crescimento da indústria bancária. Em termos de ameaças reconhece-se o risco sistêmico do setor, na medida em que o mesmo encontra-se bastante concentrado e, o colapso de um dos "grandes bancos" pode afetar fortemente o setor, apesar do rigoroso controle do Bacen e dos sólidos fundamentos apresentados por estes Bancos.

Como exemplo para ilustrar este atual bom momento dos bancos brasileiros, segundo a informação recuperada em Dezembro, 2009, de www.economatica.com.br, e, baseado nos balanços do $1^{\circ}$ o trimestre de 2009, os três bancos com maior ROE - Return on Equity ou Retorno sobre Patrimônio Liquido - da America do Norte, Central e Sul foram respectivamente o Banco do Brasil (5,48\%), o Bradesco $(4,95 \%)$ e o Itaunibanco $(5,54 \%)$ enquanto que o melhor americano foi o banco American Express (3.16\%) e Wells Fargo (3\%). Dos "grandes players" americanos apenas o Bank of América $(2,04 \%)$ e o Goldman Sachs $(2,84 \%)$ apresentaram, pela primeira vez, resultados positivos e vale ressaltar que tiveram uma forte ajuda do governo americano. Jornal Valor Econômico, recuperado em Novembro, 2009, de http://www.valoronline.com.br. 
Ainda baseado em Austin (1990), os fatores sócio-culturais e demográficos são fonte de valiosa informação para a indústria. Nota-se através deste estudo que um sub-fator importante é o aumento da estrutura etária da população de acordo com dados do IBGE - recuperado em Outubro, 2009, de http://www.ibge.gov.br. 0 envelhecimento da população pode ser uma oportunidade de aumento da oferta de produtos dedicados a tal público, favorecendo a complementaridade interna do banco com suas agências e portfolio de produtos.

A dinâmica de como a sociedade vem se estruturando reforça cada vez mais a necessidade de dedicação diária ao trabalho, com jornadas longas que às vezes ultrapassam dez horas. Esta realidade vivenciada pela população ativa, explica a cada vez maior necessidade de acessos remotos aos seus bancos, não havendo condições de visitas a agências. Isto se apresenta como uma oportunidade para os serviços eletrônicos do banco, mas também pode apresentar-se como uma ameaça caso o banco não busque inovações constantes na área de tecnologia da informação e comunicação - TIC.

Na necessidade de uma complementação à análise já feita, o presente estudo demonstra a implicação de outros atores estratégicos que influenciam a análise da indústria.

\section{OS NOVOS ENTRANTES}

As barreiras aos novos entrantes

A condição política do país impõe uma grande barreira de entrada a novos bancos no mercado brasileiro com seus fortes órgãos regulatórios. Uma outra barreira de entrada que se evidencia até hoje é a operação em escala deste tipo de indústria, representando uma barreira ao novo entrante.

A grande barreira percebida durante a pesquisa é que enquanto os concorrentes locais movimentaram-se para fusões e aquisições de um número maior de bancos, o HSBC limitou-se a aquisição do Banco Bamerindus no Brasil.

\section{Os concorrentes e complementores}

Nos últimos 12 meses além da fusão do Unibanco com o Banco Itaú outros negócios menores aconteceram como a compra da Nossa Caixa Nosso Banco e de $50 \%$ do banco Votorantim, ambos os negócios feitos pelo Banco do Brasil, fazendo com que a liderança oscilasse várias vezes entre alguns concorrentes, tais como: o Itaunibanco, Banco do Brasil e Bradesco (Editora Três, 2009).

Os bancos brasileiros passaram a ter um valor de mercado e uma capitalização importante em termos globais passando a potenciais "compradores" de bancos em outros paises.

De acordo com informações divulgadas no site Portal Exame, recuperado em Setembro, 2009, de http://www.portalexame.com.br ,o Itaúnibanco está estrategicamente se posicionado para ser um player internacional. Divulgou suas negociações para adquirir o Banamex, um dos maiores bancos mexicanos controlado pelo Citigroup, e, na América Latina o mesmo já possui uma posição relevante em vários países, principalmente na Argentina onde já é o maior banco privado.

O Banco do Brasil, além das aquisições mencionadas, está se posicionado fortemente em serviços financeiros como seguros e previdência privada. O Bradesco, após a compra do Banco Ibi, braço financeiro das lojas C\&A, na impossibilidade de poder crescer mais por aquisições no atual cenário já bastante consolidado, optou por um crescimento orgânico, abrindo filiais em todos os municípios brasileiros tentando participar ativamente no processo de incorporação de novas pessoas na economia Jornal Valor Econômico, recuperado em Outubro, 2009, de http://www.valoronline.com.br.

Segundo declarações do Presidente do Bradesco, o Sr. Luiz Trabucco, cerca de 100 milhões de pessoas irão mudar de classe social nos próximos 20 anos, $60 \%$ deste grupo ainda não está na idade produtiva. O Banco aposta na capilaridade, logística/distribuição e treinamento da sua equipe de gerentes 
abrindo cerca de 6000 novas contas todos os dias de pessoas que ainda não são correntistas - cerca de 8 milhões de contratos inferiores a $\mathrm{R} \$ 500,00$ - um dos maiores exemplos de microcrédito do mundo (Fonte: Revista Exame, 21/10/09).

O Bradesco hoje possui cerca de 21 milhões de contas correntes e imagina que o processo de inclusão social, mantido o atual market share de $20 \%$, deverá trazer cerca de 20 milhões de novos clientes até 2040. Este cenário de um aumento potencial de 100 milhões de novos clientes passou a ser um dos principais focos estratégicos dos bancos. Nesse aquecimento estão o credito ao consumidor e a habitação - o credito imobiliário hoje e de 3,5\% do PIB e deverá chegar a cerca de $12 \%$ em 2020 - que deverão ter os maiores crescimentos. (Editora Três, 2009).

O banco continua com a parceria com os complementores externos Visa e Mastercard, e internos, tais como sua financeira - Losango -, e empresas de seguro e consórcio, reforçando a política de complementaridade dos bancos de varejo no Brasil.

\section{PERFORMANCE FINANCEIRA}

Acompanhando o aquecimento da economia promovido por ações fiscais governamentais no setor automotivo e alguns bens de consumo, os bancos do Brasil tiveram resultados surpreendentes neste cenário mundial, mostrando a eficiência da gestão.

A tabela a seguir demonstra o desempenho dos principais bancos no Brasil, no período de 2006 a 2008. O HSBC Brasil vem mantendo os principais indicadores de rentabilidade iguais aos principais bancos brasileiros mais antigos e capilarizados no país, e superando largamente os concorrentes estrangeiros Santander e Citibank.

Tabela 7: Desempenho dos principais bancos brasileiros - período 2006-2008

\begin{tabular}{|c|c|c|c|c|c|c|}
\hline 2006 & & & $\mathrm{Ba}$ & os & & \\
\hline Indicadores & HSBC & $\mathrm{BB}$ & CEF & Bradesco & Itauunibanco & Santander \\
\hline $\begin{array}{c}\text { Total de Ativos } \\
\text { Op.de Credito } \\
\text { Lucro Líquido } \\
\text { ROE }\end{array}$ & $\begin{array}{c}58907612 \\
20106430 \\
939189 \\
0,23\end{array}$ & $\begin{array}{c}296356419 \\
117983446 \\
6043777 \\
0,29\end{array}$ & $\begin{array}{c}209532836 \\
16427809 \\
2386190 \\
0,26\end{array}$ & $\begin{array}{c}265547273 \\
81465152 \\
5054040 \\
0,21\end{array}$ & $\begin{array}{c}209691160 \\
51416792 \\
4308927 \\
0,18\end{array}$ & $\begin{array}{c}102027099 \\
33871562 \\
803619 \\
0,10\end{array}$ \\
\hline
\end{tabular}

\begin{tabular}{|c|c|c|r|r|r|r|}
\hline 2007 & \multicolumn{4}{|c|}{ Bancos } \\
\hline Indicadores & HSBC & BB & CEF & Bradesco & Itauunibanco & Santander \\
\hline Total de Ativos & 71.540 .720 & 357.750 .243 & 253.575 .011 & 341.184 .404 & 294.876 .251 \\
Op.de Credito & 25.680 .330 & 143.855 .175 & 50.798 .315 & 110.439 .705 & 111.015 .051 & 39.122 .182 \\
Lucro Líquido & 1.234 .054 & 5.058 .119 & 2.392 .454 & 8.009 .724 & 8.473 .604 & 1.845 .396 \\
ROE & 0,25 & 0,21 & 0,23 & 0,26 & 0,29 & 0,20 \\
\hline
\end{tabular}

\begin{tabular}{|c|c|c|c|c|c|c|}
\hline 2008 & \multicolumn{6}{|c|}{ Bancos } \\
\hline Indicadores & HSBC & $\mathrm{BB}$ & CEF & Bradesco & Itauunibanco & Santander \\
\hline $\begin{array}{l}\text { Total de Ativos } \\
\text { Op.de Credito } \\
\text { Lucro Líquido }\end{array}$ & $\begin{array}{c}113047210 \\
31395993 \\
1351006\end{array}$ & $\begin{array}{c}521272817 \\
198206085 \\
8802869\end{array}$ & $\begin{array}{c}295920330 \\
73162371 \\
3883289\end{array}$ & $\begin{array}{c}454413043 \\
133270808 \\
7620238\end{array}$ & $\begin{array}{c}632728403 \\
231060075 \\
7803483\end{array}$ & $\begin{array}{c}340635472 \\
115115416 \\
1580613\end{array}$ \\
\hline ROE & 0,22 & 0,29 & 0,31 & 0,22 & 0,18 & 0,03 \\
\hline
\end{tabular}

Fonte: Bacen - Banco Central do Brasil - www.bcb.org.br - recuperado em 21.11.2009

Mesmo nesse clima difícil, o HSBC tem continuado a estudar as possibilidades de crescimento, especialmente em mercados emergentes. A turbulência sem precedentes nos mercados financeiros e 0 risco de uma nova recessão mundial trouxe uma gama de intervenções e ajuda dos governos e bancos centrais em todo o globo. O HSBC manteve-se como um dos poucos bancos globais que não teve absolutamente nenhuma ajuda . Para reforçar seu patrimônio em novembro deste ano anunciou um reforço de capital dos seus próprios acionistas de 18 bilhões de Euros. Naturalmente o banco teve que se ajustar ao novo cenário, principalmente nos USA onde através da sua subsidiária de Personal Financial Services ( empréstimos, hipotecas, cartões de crédito etc) a Household Inc. reportou um 
prejuízo antes de impostos da ordem de US\$ 19,9 bilhões em 2008. HSBC Holding - Annual Review, recuperado em Outubro, 2009, de www.hsbc.com . Na divulgação do seu balanço o atual CEO Stephen Green, anunciou as dificuldades de ajuste ao novo cenário americano que culminou com mais de 6 mil demissões e fechamento de centenas de agências nos USA, e também na Europa. Porem citou a importância da capitalização do grupo, da sua base acionária e da manutenção dos seus principais objetivos estratégicos nos países emergentes e sua preocupação com alguns setores mais atingidos, criando um fundo global de $\$ 5$ bilhões para as pequenas e médias empresas, a fim de garantir que as mesmas tenham acesso ao crédito adequado na atual conjuntura econômica.

\section{CONCLUSÕES}

De acordo com o princípio de fit estratégico, é preciso assegurar uma coerência e consistência entre todos os fatores estrategicamente significativos para a empresa, de modo a implantar com sucesso sua estratégia e, assim, otimizar seu desempenho .No cenário atual de mudanças crescentes como foi o caso do período 2005 a 2009, o HSBC, se adequou de forma dinâmica em alguns fatores e, em outros, mostrou-se totalmente estagnado se comparado ao período estudado no artigo de Macedo-Soares (2005).

A análise comparativa com o período que foi pesquisado e evidenciado no trabalho de Macedo-Soares (2005) demonstra que o banco não evoluiu em alguns fatores internos, a saber: (a) continua havendo uma orientação da cultura da empresa voltada para resultados financeiros, não se preocupando com indicadores que demonstrem a preocupação com a satisfação dos clientes. Tal demonstração está em desacordo com a estratégia de diferenciação por preço, a qual reforça a necessidade de criação de valor para os clientes.

Apesar de o banco possuir toda a infra-estrutura tecnológica que dá suporte a um sistema de gerenciamento com o cliente, não existe foco para gerar e controlar relatórios que possam demonstrar, se a satisfação dos clientes está sendo atendida.

Os processos funcionais do HSBC, apesar de divulgados pela organização, continuam não viabilizando uma flexibilização por parte das áreas e seus gestores, o que dificulta um comportamento voltado para o empowerment. Da mesma forma o estilo autocrático de liderança continua não prezando pela iniciativa dos colaboradores e, percebe-se um desânimo muito grande por parte de alguns gestores, fato este compreensível diante de um cenário de elevado índice de demissões no HSBC Mundial.

Um dos pontos fortes do HSBC Brasil continua sendo o compromisso ético dos gestores com as práticas financeiras e de responsabilidade sócio-ambiental. É importante também ressaltar uma análise dos fatores externos do segmento naquele cenário, constatando-se o seguinte:

No geral, os bancos brasileiros foram extremamente ágeis no momento em que culminou a crise mundial. Os bancos privados rapidamente revisaram suas carteiras de crédito, aumentaram suas provisões e também seus spreads, cortaram custos, revisaram seus objetivos estratégicos (começando a olhar como compradores) agora diante de um novo cenário mundial.

Os bancos públicos de maneira um pouco diferente, mas igualmente com sucesso, em apoio as ações do governo, não diminuíram seu ritmo de empréstimos, mantiveram juros estáveis ou menores o que fez aumentar a sua base de clientes, o que fez o Banco do Brasil passar a ser o maior banco brasileiro.

De forma geral as ações de apóio fiscal e incentivos do governo, tiveram um efeito positivo na economia brasileira baseado em estatísticas do governo em que o PIB 2009 deve crescer entre 2 e $3 \%$ com projeções de alcançar 5\% em 2010, superando largamente os USA ( $0,1 \%$ em 2009) e os principais países da Europa Segundo projeções do FMI, o PIB mundial sofrerá uma contração de 1,3\% Jornal do Brasil, recuperado em Setembro,2009, de http://www.jbonline.com.br. A crise está mudando o cenário econômico mundial, e a manutenção do crescimento mundial deve vir dos BRICS principalmente dos seus mercados internos que ainda encontram muitas oportunidades. Diante deste 
cenário, o HSBC encontra-se muito bem posicionado com a sua forte presença nesses mercados emergentes. Ainda percebe-se que as oportunidades existentes são advindas dos fatores político e econômico do país e da indústria.

\section{REFERÊNCIAS BIBLIOGRÁFICAS}

AUSTIN, J. E. - Managing in developing countries. New York: Free Press, 1990

BARNEY, J. B. Gaining and sustaining competitive advantage. Reading, MA : Addison -Wesley, 1996. BRADENBURGER,A.M. \& NALEBUFF, B.J. - Co-opetition. New York: Doubleday, 1997.

CAPELLETO e CORRAR, Indíces de risco sistêmico para o setor bancário - R.Cont.Fin - USP - Vol 19 no 47 - p.6-18 - mai/ago., 2008.

DOZ, Y. L.; HAMEL, G. Alliance advantage: the art of creating value through partnering. Boston: Harvard Business School Press, 1998.

EDITORA CONFIANÇA (2009). Revista Carta Capital. São Paulo.

EDITORA ABRIL(2009) - Revista Exame - Melhores e Maiores: as 500 maiores empresas do país Edição 2007-2008 - São Paulo - SP: Autor

EDITORA ABRIL(2009) - Revista Exame - São Paulo - SP: Autor

FAHEY \& RANDALL, Learning from the future, New York, John Wiley \& Sons, 1998.

FORTUNA, E. Mercado Financeiro: produtos e serviços, Qualitymark Editora. 17aㅡ ed, p.821, Rio de Janeiro, 2009.

GULATI, R., NOHRIA, N., ZAHEER, A. Strategic networks. Strategic Management Journal, v.21,p. 203215, 2000.

HOFER.C \& SCHENDEL,D. - Strategy Formulation: Analytical Concepts. West, St. Paul, 1978.

KALE,P. \& SINGH, H. - Managing Strategic alliances: What do we know now, and where do we go from here. - Academy of Management - p.45-62 - August 2009.

MACEDO-SOARES, T. Diana L. v. A. \& Chamone, S. G. Total quality strategies in industry: the experience of two multinationals in Brazil. Quality Management Journal, v. 1, n.3, pp. 57-79, 1994.

MACEDO-SOARES, T. Diana. L. v. A. \& Lucas, D. C. - Key quality management practices of leading firms in Brazil: Findings of a pilot-study. The TQM Magazine, v. 8, n. 4, pp. 55-70, 1996.

MACEDO-SOARES, T. Diana. L. v. A. - An integrative model for strategic management analysis: Application to organizations in Brazil. Proceedings of INFORMS-KORMS Conference, Seoul, pp.

460-467, 2000.

MACEDO SOARES - Assessing Competitive Strategies of foreign banks in Latin América: The case of HSBC Bank of Brazil - Journal of Global Business and Technology - v.1, n.1, Spring- p.1.13 - 2005.

MINTZBERG,G. H. - Generic strategies. In: Advances on Strategic Management. JAI Press, v. 5, pp. 167, 1988.

PORTER, M. - Competitive strategy: Techniques for analyzing industries and competitors. New York: Free Press, 1980.

ROSS, S. A.; WESTERFIELD, R. W.; JAFFE, J. F. Administração financeira: corporate fi nance. Tradução de Antonio Z. Sanvicente. São Paulo: Atlas, 1995.

WERNEFELT, B. A. - A resource-based view of the firm. Strategic Management Journal, v. 5, n. 2, pp. 171-180, 1984. 